\title{
Review \\ Mechanical Ventilation Strategies in the Critically Ill Burn Patient: A Practical Review for Clinicians
}

\author{
Jared S Folwell 1,2, Anthony P Basel 1,2,*, Garrett W Britton 1,2, Thomas A Mitchell 1,2, Michael R Rowland ${ }^{1,2}$, \\ Renford Cindass ${ }^{1,2}$, David R Lowery ${ }^{1,2}$, Alicia M Williams ${ }^{1,2}$, David S Lidwell ${ }^{1,2}$, Linda Hong ${ }^{1,2}$, \\ Jason J Nam ${ }^{2,3}$, Jonathan B Lundy ${ }^{1,2}{ }^{\circledR}$, Jeremy C Pamplin ${ }^{2,4}$ and Leopoldo C Cancio ${ }^{1}$
}

Citation: Folwell, J.S.; Basel, A.P.; Britton, G.W.; Mitchell, T.A.; Rowland, M.R.; Cindass, R.; Lowery, D.R.; Williams, A.M.; Lidwell, D.S.;

Hong, L.; et al. Mechanical

Ventilation Strategies in the Critically Ill Burn Patient: A Practical Review for Clinicians. Eur. Burn J. 2021, 2, 140-151. https://doi.org/10.3390/ ebj2030011

Academic Editors: Naiem Moiemen and Peter M. Vogt

Received: 28 June 2021

Accepted: 25 August 2021

Published: 7 September 2021

Publisher's Note: MDPI stays neutral with regard to jurisdictional claims in published maps and institutional affiliations.

Copyright: (C) 2021 by the authors. Licensee MDPI, Basel, Switzerland. This article is an open access article distributed under the terms and conditions of the Creative Commons Attribution (CC BY) license (https:/ / creativecommons.org/licenses/by/ $4.0 /)$.
1 U.S. Army Institute of Surgical Research, Fort Sam Houston, San Antonio, TX 78234, USA; jared.s.folwell.mil@mail.mil (J.S.F.); garrett.w.britton.mil@mail.mil (G.W.B.); thomas.a.mitchell.mil@mail.mil (T.A.M.); michael.r.rowland.mil@mail.mil (M.R.R.); renford.cindass.mil@mail.mil (R.C.); lowerymd@gmail.com (D.R.L.); alicia.m.williams.mil@mail.mil (A.M.W.); david.s.lidwell.mil@mail.mil (D.S.L.); linda.hong2.mil@mail.mil (L.H.); jonathan.b.lundy2.mil@mail.mil (J.B.L.); Leopoldo.c.cancio.mil@mail.mil (L.C.C.)

2 Department of Medicine, Uniformed Services University School of Medicine, Bethesda, MD 20814, USA; jason.j.nam.mil@mail.mil (J.J.N.); jeremy.c.pamplin.mil@mail.mil (J.C.P.)

3 Division of Pulmonary, Allergy, and Critical Care Medicine, Duke University Hospital, Durham, NC 27710, USA

4 U.S. Army Telemedicine and Advanced Technology Research Center, Ft. Detrick, Frederick, MD 21702, USA

* Correspondence: anthony.p.basel.mil@mail.mil

\begin{abstract}
Burn patients are a unique population when considering strategies for ventilatory support. Frequent surgical operations, inhalation injury, pneumonia, and long durations of mechanical ventilation add to the challenging physiology of severe burn injury. We aim to provide a practical and evidence-based review of mechanical ventilation strategies for the critically ill burn patient that is tailored to the bedside clinician.
\end{abstract}

Keywords: burn; thermal injury; critical care; inhalation injury; respiratory failure; mechanical ventilation; acute respiratory distress syndrome; high-frequency percussive ventilation; airwaypressure-release ventilation; noninvasive ventilation; continuous positive airway pressure; bi-level positive airway pressure; high-flow nasal cannula

\section{Introduction}

Management of critically ill burn patients in the intensive care unit (ICU) is complex. Up to $33 \%$ of burn patients admitted to the ICU will require mechanical ventilation (MV) [1]. Burn patients are a unique population when considering strategies for ventilatory support. These challenging patients commonly have concomitant inhalation injury, long durations of $\mathrm{MV}$, and increased incidence of ventilator-associated pneumonia; furthermore, they typically require multiple surgical operations. We aim to provide an evidence-based, clinical review for the bedside clinician.

\section{Common Pulmonary Problems Associated with Burn Injury \\ 2.1. Inhalation Injury}

Inhalation injury is an independent predictor of mortality after thermal injury irrespective of burn size or age $[2,3]$ and occurs in $10-15 \%$ of patients admitted to burn centers $[4,5]$. In the United States, in-hospital mortality related to inhalation injury can exceed 50\% in patients with thermal injuries of greater than $50 \%$ of the total body surface area (TBSA) [2]. Inhalation injury can be subdivided into 3 categories: upper airway injury, lower airway and parenchymal injury, and metabolic toxicity caused by carbon monoxide or hydrogen cyanide [6]. Smoke inhalation induces cellular injury, igniting an inflammatory cascade 
that results in bronchorrhea, formation of obstructing tracheobronchial casts, atelectasis, ventilation-perfusion mismatch, and hypoxic respiratory failure. At the same time, it causes impairment of pulmonary immune function and sets the stage for bacterial pneumonia $[2,7]$. Inhalation injury is both one of the leading indications for mechanical ventilation in burn injury, and a leading contributor to prolonged mechanical ventilation [2-5].

\subsection{Acute Respiratory Distress Syndrome}

ARDS occurs in $2-17 \%$ of burn patients. Age, injury severity score (ISS), acute kidney injury, and pneumonia are risk factors for the development of moderate-to-severe ARDS [8,9]. Compared to other causes of ARDS, the onset of ARDS in burn patients may be delayed up to 24 days $[10,11]$. The timing of postburn ARDS varies with etiology. Early after burn, ARDS may be caused by severe inhalation injury and/or by extensive cutaneous burns. Later postburn, ARDS is often caused by pneumonia or other infections [8]. ARDS is another common pulmonary complication in burn patients that contributes to prolonged mechanical ventilation [8-10].

\section{Who Requires Intubation?}

During the management of critically ill burn patients, the bedside clinician must remain vigilant for airway compromise and establish an airway in any burn patient with the following: burns over $40 \%$ total body surface area (TBSA), respiratory distress with signs of accessory muscle use or fatigued appearance, or a Glasgow Coma Scale (GCS) $<8[6,12,13]$. Clinicians should be leery of patients with "classic signs" of inhalation injury (stridor, head/neck burns, carbonaceous sputum, hoarseness, intraoral mucosal injury), especially in combination with burns $\geq 20 \%$ TBSA, large areas of full-thickness burns, and/or circumferential burns to the chest or abdomen. These patients can decompensate quickly and without warning during their resuscitation. Importantly, edema formation typically peaks at 12-24 h after injury [14] and is an important factor to consider when evaluating for impending respiratory failure.

\section{Conventional Lung-Protective Ventilation}

Mechanisms that lead to ventilator-induced lung injury (VILI) include high tidal volumes (volutrauma), high inspiratory pressures (barotrauma), repeated opening and closing of alveoli (atelectrauma), high mechanical power (ergotrauma), oxygen toxicity, and inflammatory cytokine release (biotrauma) [15-18]. Low-tidal-volume ventilation reduces the incidence of VILI by minimizing these mechanisms. Targeting $6 \mathrm{~mL} / \mathrm{kg}$ of ideal body weight (IBW) reduces mortality in patients with acute respiratory distress syndrome (ARDS) $[15,16]$. The ALVEOLI study demonstrated that high- vs. low-PEEP strategies had similar outcomes if TV was $6 \mathrm{~mL} / \mathrm{kg}$ IBW and plateau pressure (Ppl) was limited to $30 \mathrm{~cm} \mathrm{H}_{2} \mathrm{O}$ [15]. Recently, minimizing driving pressure ( $\triangle \mathrm{P}=$ Ppl-PEEP) and targeting $\Delta \mathrm{P} \leq 15 \mathrm{~cm} \mathrm{H}_{2} \mathrm{O}$ demonstrated an improvement in mortality [16].

Notwithstanding those findings in other patient populations, low-tidal-volume ventilation is associated with some practical challenges in burn patients. Inhalation injury causes mucosal sloughing, copious secretions, and hemorrhage requiring aggressive pulmonary toilet to clear the airway $[19,20]$. Fluid resuscitation may result in pulmonary edema or intraabdominal hypertension. Hypermetabolism from extensive burn injury increases carbon dioxide production, making adherence to low-tidal-volume ventilation difficult. Thus, alternative modes such as high-frequency percussive ventilation or airway-pressure-release ventilation are used in many burn centers $[5,21,22]$.

\section{Alternative Modes of Ventilation}

\subsection{High-Frequency Percussive Ventilation}

The Volumetric Diffusive Respirator (VDR-4; Percussionaire, Corp., Sandpoint, ID) is a pneumatically driven, flow-regulated, and time-cycled ventilator which provides highfrequency percussive ventilation (HFPV). It is pneumatically driven in that the ventilator 
itself (as opposed to the monitor) requires only a pressurized gas source for operation. It is flow regulated in that the user adjusts not the inspiratory pressure or the tidal volume, but rather adjusts the inspiratory flow delivered to the patient to achieve a given peakinspiratory pressure. This means that changing resistance (e.g., stiffer lungs) can affect delivered pressures and volumes, mandating periodic checks by the respiratory therapist. It is time cycled in that the user determines the set respiratory rate by adjusted inspiratory and expiratory times. Timing is not determined by the patient. Rather, patient-ventilator synchrony is facilitated by other design features (see below).

In a sense, HFPV can be conceptualized as similar to a pressure-controlled mode in which a high-frequency rate (e.g., 400-600 breaths per $\mathrm{min}$ ) is superimposed-throughout the respiratory cycle - on a low-frequency rate (e.g., 0-30 breaths per min). More accurately, HFPV interfaces with the patient's endotracheal tube via a sliding venturi (the Phasitron) which entrains gas from a bias-flow circuit. The Phasitron delivers successive high-frequency, flow-interrupted, sub-tidal breaths which are stacked until an oscillatory apneustic plateau is reached at full inspiration. At the conclusion of the inspiratory phase, passive exhalation then occurs.

The open-circuit design with the sliding Phasitron allows patients to maintain spontaneous respiration throughout the respiratory cycle, thus increasing patient-ventilator synchrony and potentially augmenting minute ventilation [2]. The percussive aspect of this mode of ventilation improves the clearance of secretions and helps recruit collapsed alveoli (Figure 1). The high-frequency ("diffusive") component of this mode improves gas mixing and achieves oxygenation at lower peak airway pressures, whereas the low-frequency ("volumetric") component of this mode achieves clearance of carbon dioxide.
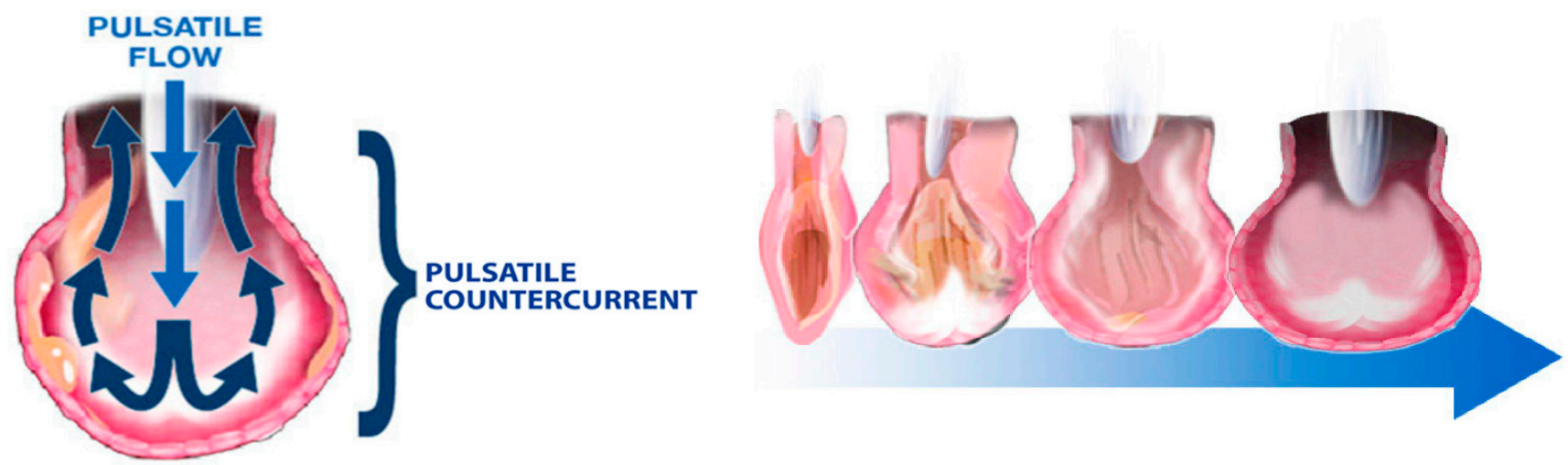

\section{Pulsatile Flow}

The flow created by the Phasitron $®$ is known as Pulsatile Flow which bathes the alveoli in fresh oxygenated air while gently washing out $\mathrm{CO} 2$ and secretions. HFPV is a Pulsatile Flow that mobilizes and removes mucus and debris, while gently recruiting alveoli and restoring FRC. Unlike external percussion that may drive secretions deeper into the lung, the Pulsatile Flow continues to dislodge debris and secretions which are carried out by the exiting airflow.

Figure 1. This diagram depicts pulsatile flow created by the HFPV at the alveolar level and how it aids in alveolar recruitment and debris mobilization.

Evaluation of this mode by Cioffi et al. demonstrated an improvement in mortality and decreased prevalence of pneumonia in burn patients with inhalation injury, in comparison to age- and burn-size-adjusted historical controls [23]. Chung et al. conducted a single-center prospective randomized controlled trial of HFPV vs. low-tidal-volume ventilation in burn patients. They found no difference in mortality, but a higher rate of rescue to another form of ventilation in the low-tidal-volume group [5]. More prospective randomized studies are needed to evaluate the use of HFPV as a primary ventilator strategy. However, it is routinely used in burn centers including the U.S. Army Burn Center, particularly in patients with inhalation injury or who fail conventional modes of ventilation (Figure 2) $[2,6]$. 


\section{High Frequency Percussive Ventilation (HFPV)}

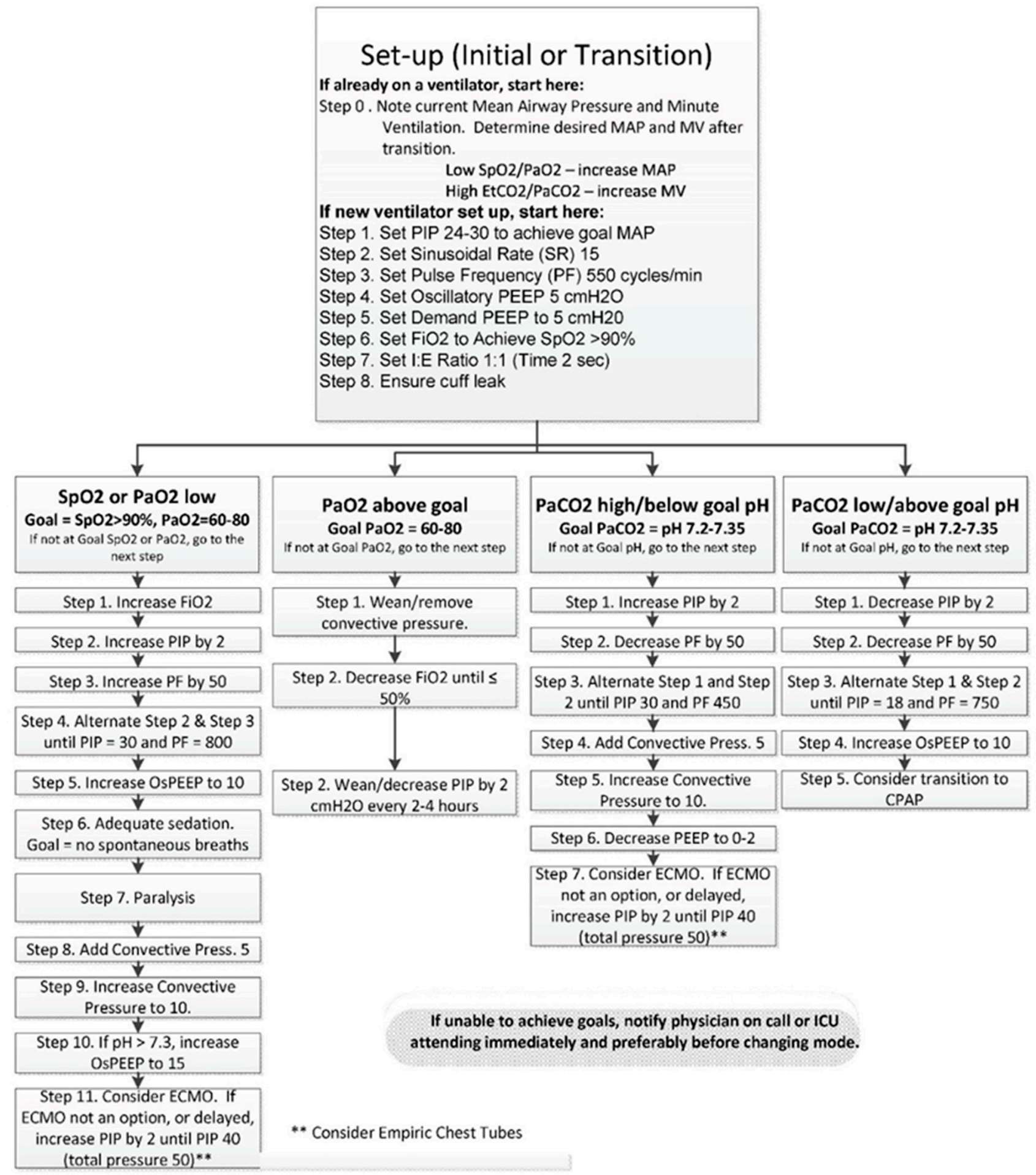

Figure 2. The U.S. Army Burn Center's algorithm of initiating, managing and weaning HFPV. 
High-frequency oscillatory ventilation (HFOV) is a mode of MV which shares some features with HFPV [24]. Although HFOV is no longer recommended for the treatment of ARDS in adults $[25,26]$ or children [27], it has been used for children with burns and/or inhalation injuries [28-30]. Most literature regarding the use of HFOV in this population has been limited to small, single-center, retrospective studies [28]. In those studies, HFOV was associated with reduced prevalence of pneumonia, lower peak-inspiratory pressures, improved oxygenation, and decreased work of breathing when applied to pediatric burn patients early in their disease course [28-30].

Most of these centers state that HFOV should be considered in pediatric patients with greater than $40 \%$ TBSA in the first $36 \mathrm{~h}$ postburn [28,31]. As with HFPV, future prospective evaluation would be needed to more clearly define HFOV utility [31].

\subsection{Airway-Pressure-Release Ventilation}

Airway-pressure-release ventilation (APRV) is an option for burn patients, particularly for those with ARDS or who fail conventional modes. Stock et al. initially described APRV in an animal model with induced acute lung injury (ALI) as a continuous positive-airwaypressure (CPAP) mode with periodic releases in the pressure to enhance ventilation [32]. Habashi et al. described "personalized" APRV by prolonging $\mathrm{T}_{\text {high }}$, with a brief $\mathrm{T}_{\text {low }}$ targeting expiratory flow [33].

Specific evidence supporting the use of APRV in the burn population is lacking. Interestingly, in a porcine model of severe smoke inhalation injury, Batchinsky and colleagues found that APRV-treated animals developed ARDS faster than those treated with conventional volume-controlled ventilation [7]. Proponents argue that APRV improves alveolar recruitment and stability, improves ventilation-perfusion matching, increases mean airway pressure, minimizes peak and plateau pressures, preserves spontaneous breathing, and reduces sedation requirements [34-36]. Reduced sedation preserves airway reflexes and cough, and has the theoretical benefits in burn patients of reducing ventilator-associated pneumonia and increasing rehabilitation performance. Further study of APRV, with clearly defined standards and protocols is needed to establish a clear benefit over conventional strategies. We routinely use APRV at the US Army Burn Center (Figure 3). 


\section{Airway Pressure Release Ventilation (APRV)}

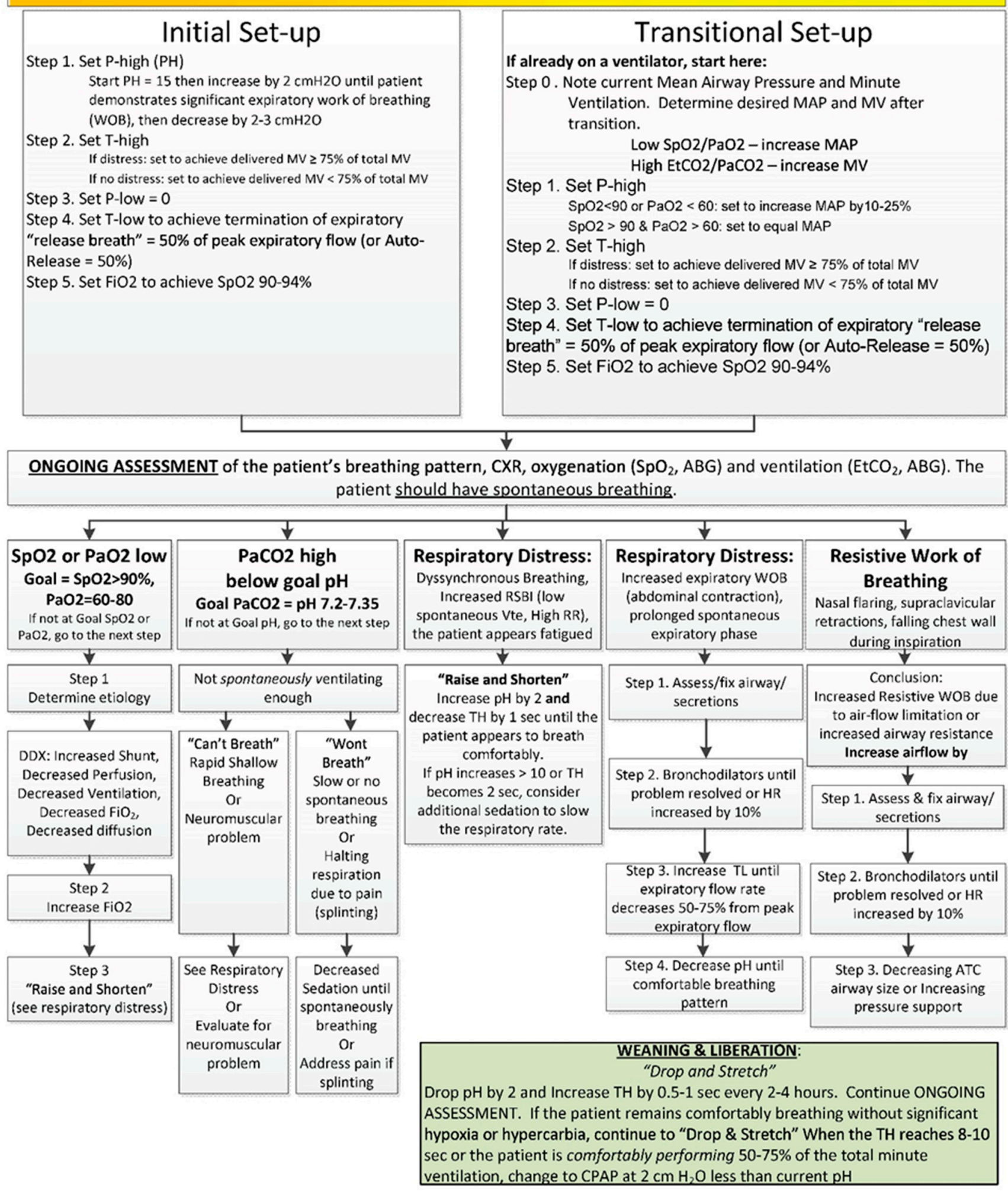

Figure 3. The U.S. Army Burn Center's algorithm of initiating, managing and weaning APRV. 


\section{Spontaneous Awakening and Breathing Trials}

Unless otherwise contraindicated, mechanically ventilated burn patients should undergo daily sedation interruptions and spontaneous breathing trials [13]. A spontaneous awakening trial (SAT) is a period during which sedating medications are held in order to determine the need for ongoing sedation [37]. A spontaneous breathing trial (SBT) is a period during which MV is decreased to a minimal level of support to determine whether the patient requires ongoing MV [37]. In the landmark ABC Trial, a daily paired SAT and SBT protocol for mechanically ventilated ICU patients improved ventilator-free days, ICU length of stay, and 1-year mortality [38]. Similar results were seen in a retrospective review at one burn ICU after the implementation of a combined SAT and SBT protocol [39].

At the U.S. Army Burn Center, all mechanically ventilated patients undergo a daily safety screen followed by an SAT/SBT performed by the bedside nurse and respiratory therapist (RT) (Table 1). Safety screening criteria are consistent with those used in the ABC Trial [38] and result in cancellation of the protocol if any of the failure criteria are met. The nurse then begins the SAT by withholding all sedative and analgesic medications, except those analgesics required for active pain control. If the patient is still anxious, agitated, or in pain, infusions can be titrated back on to a Richmond Agitation Sedation Score (RASS) score of -1 or 0 . For 30 to $60 \mathrm{~min}$, the patient is observed for any failure criteria. Patients that fail the SAT are placed back on sedatives at half the previous doses then titrated to effect.

Table 1. U.S. Army Burn Center Spontaneous Awakening and Breathing Trial Protocol ${ }^{\dagger}$.

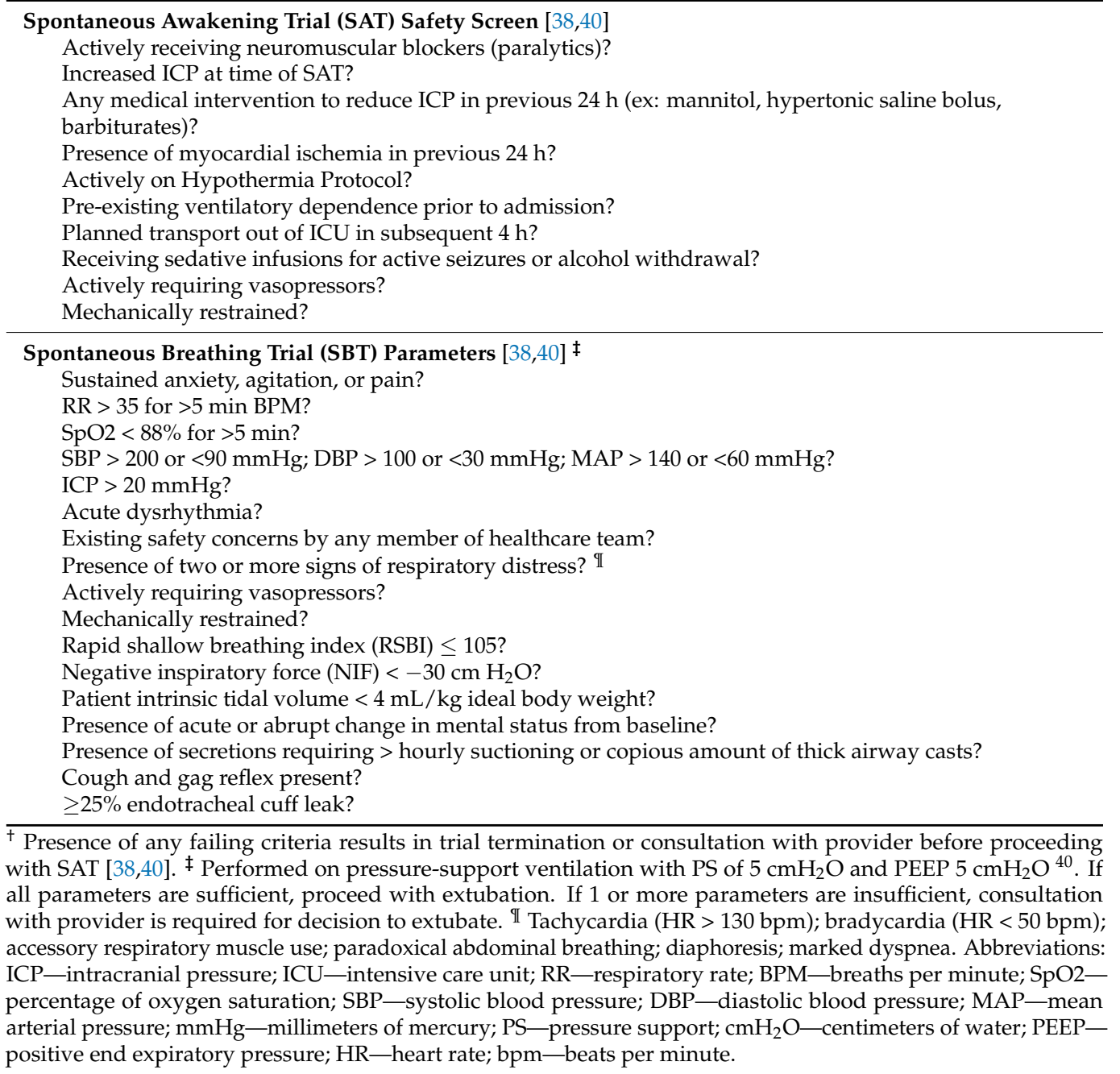


Patients that pass the initial safety screening and SAT undergo an SBT by the RT for 30-60 min. SBT ventilator settings are typically a pressure-support mode (PS) of $5 \mathrm{~cm}$ $\mathrm{H}_{2} \mathrm{O}$ and PEEP of $5 \mathrm{~cm} \mathrm{H} \mathrm{H}_{2} \mathrm{O}$. Varying pressures of PEEP and PS can be used; however, the American College of Chest Physicians/American Thoracic Society Clinical Practice Guidelines do not recommend SBT via T-piece or CPAP [40]. In addition to those used in the ABC Trial [38], our SBT failure criteria also address circumstances unique to burn patients with upper respiratory tract edema or inhalation injury: cough strength, secretion production, and cuff leak (Table 1). In a single-center prospective study, burn patients with cough peak flow of less than $60 \mathrm{~L} / \mathrm{min}$ or requiring hourly suctioning were 8-9 times more likely to fail extubation [41].

Burn patients who fail extubation have significantly longer duration of MV and length of stay [42]. Since both delayed and premature removal from MV are associated with increased mortality [43], the use of SAT and SBT protocols to determine the optimal time of extubation is beneficial and should be done daily.

\section{High-Risk Extubations}

Extubating patients is not without risk. To succeed, a patient should meet the following prerequisites: ability to protect their airway; appropriate mental status; adequate oxygenation and ventilation; Glasgow Coma Scale (GCS) score $\geq 8$; closed abdomen; and cardiovascular stability [44,45]. Hernandez et al. divided critically ill patients into low versus high risk for extubation, based on several demographic and clinical criteria [46]. Patients with a large burden of injury, large areas of deep partial or full-thickness burns, inhalation injury, and/or who have undergone a large-volume resuscitation are generally considered high risk for extubation (Table 2). When extubating patients who are high risk, airway carts, or reintubation supplies should be readily available.

Table 2. Characteristics of Burn Patients placing them at High Risk for Reintubation.

\begin{tabular}{c} 
Age $>65$ Years [47] \\
\hline Heart Failure as primary indication for mechanical ventilation [47] \\
Moderate-to-Severe COPD [47] \\
APACHE II Score $>12$ on day of extubation [47] \\
BMI $>30 \mathrm{~kg} / \mathrm{m}$ [41,47] \\
Difficult or prolonged weaning [47] \\
Mechanical ventilation $>7$ days [41,47] \\
Burn Shock with ongoing resuscitation \\
$>40 \%$ TBSA \\
$>20 \%$ TBSA mostly deep partial $/$ full-thickness burns \\
Inhalational Injury [47] \\
Increased Volume Status (Na $<140)$ \\
Cuff leak $<25 \%$ \\
Requiring suctioning equal or more frequently than hourly
\end{tabular}

\section{Noninvasive Modes of Mechanical Ventilation}

\subsection{Continuous Positive Airway Pressure (CPAP)}

Noninvasive CPAP is the administration of positive airway pressure during both inspiration and expiration in spontaneously breathing patients. The purpose of positiveairway-pressure therapy is to improve functional residual capacity (FRC), increase lung compliance, and correct VQ mismatch in hypoxemic patients [48]. CPAP results in the recruitment and expansion of partially collapsed alveoli. The subsequent decrease in pulmonary shunt improves oxygenation, reduces work of breathing, and reduces leftventricular afterload [49]. Additionally, CPAP does not require an artificial airway. Candidates for CPAP should be awake, spontaneously breathing, able to protect their airway, and hemodynamically stable. CPAP should be limited to less than $15 \mathrm{cmH}_{2} \mathrm{O}$ to mitigate the risk of gastric distention and aspiration. Excessive CPAP at pressures of greater than 
$20 \mathrm{cmH}_{2} \mathrm{O}$ can result in pulmonary barotrauma from alveolar overdistention, increased dead-space ventilation, and decreased lung compliance [50].

\subsection{Bilevel Positive Airway Pressure (BiPAP)}

BiPAP is a pressure-support mode of ventilation with PEEP in spontaneously breathing patients without an artificial airway. Patient-triggered inspiratory effort results in a set amount of pressure supplied by the ventilator (inspiratory positive airway pressure or IPAP) followed by passive expiration with PEEP (expiratory positive airway pressure or EPAP), providing a baseline of positive pressure at all times. The difference between IPAP and EPAP is the driving pressure, or amount of total pressure support. In this mode, patients control their respiratory rate in addition to inspiratory and expiratory times.

The additional pressure support during inspiration augments TV, increases FRC, and decreases the WOB [49]. Although CPAP improves oxygenation, the pressure support in BiPAP improves both oxygenation and ventilation, which makes BiPAP especially helpful in hypercarbic patients [49]. Similar to CPAP, patients on BiPAP must be awake and breathing spontaneously with intact airway reflexes. Adverse effects of BiPAP secondary to excessive pressure support include auto-PEEP, gastric distention with the potential for aspiration, pneumothorax, and delayed cycling.

There are no universally applicable recommendations for initiating BiPAP, but individual titration should be performed to improve oxygenation and decrease work of breathing. To achieve the best results when transitioning from invasive ventilation to BiPAP, attempts should be made to match the patient's required driving pressure and wean from there [51]. Meta-analyses reviewing noninvasive positive-pressure ventilation after extubation found reductions in mortality, length of stay, and rates of ventilator-associated pneumonia in post-operative patients with COPD [52].

There is currently a lack of research examining the impact of extubation to noninvasive positive-pressure modalities in the burn population. Anatomic barriers of burn patients such as facial burns, facial trauma, and facial dressings may preclude the use of CPAP or BiPAP, due to an inability to form an adequate mask seal. Prophylactic use of $\mathrm{CPAP}$ or BiPAP in appropriate patients may reduce respiratory insufficiency during burn resuscitation. On the other hand, fluid resuscitation in the initial period after a burn may result in precipitous development of airway edema. Much work remains to determine the optimal timing and application of noninvasive positive-pressure ventilation in the burn population.

\subsection{High-Flow Nasal Cannula}

High-flow nasal cannula (HFNC) has become a staple of oxygen delivery in ICUs. HFNC produces flow rates from $8 \mathrm{~L} / \mathrm{min}$ to $60 \mathrm{~L} / \mathrm{min}$ with $\mathrm{FiO}_{2}$ of 0.21 to $1.0 \mathrm{FiO}_{2}$ is adjusted as gas passes through an oxygen blender where it is heated and saturated with water via an in-line humidifier. Both flow and $\mathrm{FiO}_{2}$ are allowed to be adjusted independently of each other [53]. The humidified air is provided to the patient through soft nasal prongs providing a more comfortable experience [54]. HFNC continues to be associated with increased comfort, lower dyspnea scores and reduced mouth dryness [55]. Other benefits of HFNC include decreased secretions and enhanced secretion mobilization [56,57], reduced work of breathing $[53,58]$, improved ventilation mechanics due to washout of upper airway dead space [59], and PEEP.

Recently, several large multicenter clinical trials evaluated the use of HFNC after extubation. Five hundred and 27 critically ill patients who were deemed low risk (age $<65$ years; APACHE II $<12$ on day of extubation, BMI $<30$, absence of heart failure or moderate-to-severe COPD) were randomized to either high-flow or conventional oxygen therapy for $24 \mathrm{~h}$ after extubation. The use of HFNC oxygen compared with conventional oxygen therapy reduced the risk of reintubation within $72 \mathrm{~h} \mathrm{[46].} \mathrm{A} \mathrm{follow-on} \mathrm{study} \mathrm{eval-}$ uated whether HFNC was noninferior to noninvasive MV in patients who were deemed high risk for extubation. Although reintubation rates were the same, the HFNC group had 
significantly less postextubation respiratory failure ( $27 \%$ vs. $40 \%$ ) [47]. These 2 studies remain the largest and most compelling arguments for the use of HFNC upon extubation of critically ill patients.

No studies evaluating the use of HFNC in the burn population currently exist. Most critically ill burn patients fit into the high-risk category described by Hernandez (Table 2) [46,47]. Currently at the U.S. Army Burn Center, all burn patients who have been intubated for longer than $12 \mathrm{~h}$ are extubated to HFNC for $24 \mathrm{~h}$ unless another form of NIV is deemed more clinically appropriate.

\section{Conclusions}

In critically ill burn patients, lung-protective ventilation can be challenging but is likely beneficial and should be implemented if possible. No single ventilator strategy is considered standard of care, as the complicated aspects of burn physiology have dictated a more individualized approach [60]. Early implementation of alternative modes such as HFPV or APRV is considered accepted practice in most burn centers [60]. Further studies will be helpful to confirm clinical benefit. Upon extubation, many burn patients are at high risk for reintubation or postextubation respiratory failure, and will likely benefit from extubation to noninvasive modes such as HFNC.

Author Contributions: Conceptulazation: J.S.F., A.P.B., G.W.B., Methedology: A.P.B., G.W.B., L.C.C., Investigation: J.S.F., A.P.B., T.A.M., G.W.B., M.R.R., R.C., D.R.L., L.H., J.J.N., J.C.P., L.C.C., WritingOriginal Draft Preparation: J.S.F., A.P.B., T.A.M., G.W.B., M.R.R., R.C., D.R.L., L.H., J.B.L., J.J.N., J.C.P., L.C.C., Writing-Review and Editing: J.S.F., A.P.B., T.A.M., G.W.B., A.M.W., D.S.L., J.B.L., L.C.C., Visualization: A.P.B., L.C.C., Supervision: A.P.B., L.C.C., Project Administration: A.P.B., L.C.C. All authors have read and agreed to the published version of the manuscript.

Funding: No external funding was received.

Conflicts of Interest: Leopoldo C. Cancio has received speaker fees from Percussionaire, Inc.

Disclaimer: The opinions or assertions contained herein are the private views of the authors, and are not to be construed as official or as reflecting the views of the Department of the Army or the Department of Defense.

\section{References}

1. Belenkiy, S.M.; Buel, A.R.; Cannon, J.; Sine, C.R.; Aden, J.K.; Henderson, J.L.; Liu, N.T.; Lundy, J.B.; Renz, E.M.; Batchinsky, A.I.; et al. Acute respiratory distress syndrome in wartime military burns: Application of the Berlin criteria. J. Trauma Acute Care Surg. 2014, 76, 821-827. [CrossRef] [PubMed]

2. Miller, A.C.; Ferrada, P.A.; Kadri, S.S.; Nataraj-Bhandari, K.; Vahedian-Azimi, A.; Quraishi, S.A. High-frequency ventilation modalities as salvage therapy for smoke inhalation-Associated acute lung injury: A systematic review. J. Intensive Care Med. 2018, 33, 335-345. [CrossRef] [PubMed]

3. Walker, P.F.; Buehner, M.F.; Wood, L.A.; Boyer, N.L.; Driscoll, I.R.; Lundy, J.B.; Cancio, L.C.; Chung, K.K. Diagnosis and management of inhalation injury: An updated review. Crit. Care 2015, 19, 1-12. [CrossRef] [PubMed]

4. Chao, K.-Y.; Lin, Y.-W.; Chiang, C.-E.; Tseng, C.-W. Respiratory management in smoke inhalation injury. J. Burn Care Res. 2019, 40, 507-512. [CrossRef]

5. $\quad$ Chung, K.K.; Wolf, S.; Renz, E.M.; Allan, P.F.; Aden, J.K.; Merrill, G.A.; Shelhamer, M.C.; King, B.T.; White, C.E.; Bell, D.G.; et al. High-frequency percussive ventilation and low tidal volume ventilation in burns: A randomized controlled trial. Crit. Care Med. 2010, 38, 1970-1977. [CrossRef] [PubMed]

6. Cancio, L.C. Airway management and smoke inhalation injury in the burn patient. Clin. Plast. Surg. 2009, 36, 555-567. [CrossRef]

7. Batchinsky, A.I.; Burkett, S.E.; Zanders, T.B.; Chung, K.K.; Regn, D.D.; Jordan, B.S.; Necsoiu, C.; Nguyen, R.; Hanson, M.A.; Morris, M.J.; et al. Comparison of airway pressure release ventilation to conventional mechanical ventilation in the early management of smoke inhalation injury in swine. Crit. Care Med. 2011, 39, 2314-2321. [CrossRef] [PubMed]

8. Dancey, D.R.; Hayes, J.; Gomez, M.; Schouten, D.; Fish, J.; Peters, W.; Slutsky, A.S.; Stewart, T.E. ARDS in patients with thermal injury. Intensive Care Med. 1999, 25, 1231-1236. [CrossRef]

9. Sine, C.R.; Belenkiy, S.M.; Henderson, J.L.; Aden, J.K.; Batchinsky, A.; Cancio, L.C.; Chung, K.K.; Buel, A.R.; Waters, J.A.; Lundy, J.B.; et al. Acute respiratory distress syndrome in burn patients: A comparison of the Berlin and American-European definitions. J. Burn Care Res. 2016, 37, e461-e469. [CrossRef]

10. Pruitt, B.A.; Flemma, R.J.; DiVincenti, F.C.; Foley, F.D.; Mason, A.D.; Young, W.G., Jr. Pulmonary complications in burn patients. A comparative study of 697 patients. J. Thorac. Cardiovasc. Surg. 1970, 59, 7-20. [CrossRef] 
11. Tranbaugh, R.F.; Elings, V.B.; Christensen, J.M.; Lewis, F.R. Effect of inhalation injury on lung water accumulation. J. Trauma Inj. Infect. Crit. Care 1983, 23, 597-604. [CrossRef] [PubMed]

12. Driscoll, I.M.-S.E.; Pamplin, J.; Cancio, L. Burn Care (CPG ID: 12); Joint Trauma System, United States of America Department of Defense: 2016. Available online: https://jts.amedd.army.mil/assets/docs/cpgs/Burn_Care_11_May_2016_ID12.pdf (accessed on 24 August 2021).

13. Herndon, D.N. Total Burn Care; Elsevier: Amsterdam, The Netherlands, 2018.

14. Demling, R.H. The burn edema process: Current concepts. J. Burn. Care Rehabil. 2005, 26, 207-227.

15. Acute Respiratory Distress Syndrome, N.; Brower, R.G.; Matthay, M.A.; Morris, A.; Schoenfeld, D.; Thompson, B.T.; Wheeler, A. Ventilation with lower tidal volumes as compared with traditional tidal volumes for acute lung injury and the acute respiratory distress syndrome. N. Engl. J. Med. 2000, 342, 1301-1308. [CrossRef]

16. Amato, M.B.P.; Barbas, C.; Medeiros, D.M.; Magaldi, R.B.; Schettino, G.P.; Lorenzi-Filho, G.; Kairalla, R.; Deheinzelin, D.; Munoz, C.; Oliveira, R.; et al. Effect of a protective-ventilation strategy on mortality in the acute respiratory distress syndrome. N. Engl. J. Med. 1998, 338, 347-354. [CrossRef] [PubMed]

17. Brower, R.G.; Lanken, P.N.; MacIntyre, N.; Matthay, M.A.; Morris, A.; Ancukiewicz, M.; Schoenfeld, D.; Thompson, B.T. Higher versus Lower positive end-expiratory pressures in patients with the acute respiratory distress syndrome. N. Engl. J. Med. 2004, 351, 327-336. [CrossRef] [PubMed]

18. Marini, J.J.; Jaber, S. Dynamic predictors of VILI risk: Beyond the driving pressure. Intensive Care Med. 2016, 42, 1597-1600. [CrossRef]

19. Albright, J.M.; Davis, C.S.; Bird, M.D.; Ramirez, L.; Kim, H.; Burnham, E.L.; Gamelli, R.L.; Kovacs, E.J. The acute pulmonary inflammatory response to the graded severity of smoke inhalation injury. Crit. Care Med. 2012, 40, 1113-1121. [CrossRef]

20. Head, J.M. Inhalation injury in burns. Am. J. Surg. 1980, 139, 508-512. [CrossRef]

21. Glas, G.J.; Horn, J.; Van Der Hoeven, S.M.; Hollmann, M.W.; Cleffken, B.; Colpaert, K.; Juffermans, N.P.; Knape, P.; Loef, B.G.; Mackie, D.P.; et al. Changes in ventilator settings and ventilation-induced lung injury in burn patients-A systematic review. Burns 2019, 46, 762-770. [CrossRef]

22. Palazzo, S.; James-Veldsman, E.; Wall, C.; Hayes, M.; Vizcaychipi, M. Ventilation strategies in burn intensive care: A retrospective observational study. Burn. Trauma 2014, 2, 29-35. [CrossRef]

23. Cioffi, W.G., Jr.; Rue, L.W. Diagnosis and treatment of inhalation injuries. Crit. Care Nurs. Clin. N. Am. 1991, 3, 191-198. [CrossRef]

24. Pillow, J. High-frequency oscillatory ventilation: Mechanisms of gas exchange and lung mechanics. Crit. Care Med. 2005, 33, S135-S141. [CrossRef]

25. Fan, E.; Del Sorbo, L.; Goligher, E.C.; Hodgson, C.L.; Munshi, L.; Walkey, A.J.; Adhikari, N.K.; Amato, M.B.; Branson, R.; Brower, R.G.; et al. An Official American Thoracic Society/European Society of Intensive Care Medicine/Society of Critical Care Medicine Clinical Practice Guideline: Mechanical ventilation in adult patients with acute respiratory distress syndrome. Am. J. Respir. Crit. Care Med. 2017, 195, 1253-1263. [CrossRef]

26. Narendra, D.K.; Hess, D.R.; Sessler, C.N.; Belete, H.M.; Guntupalli, K.K.; Khusid, F.; Carpati, C.M.; Astiz, M.E.; Raoof, S. Update in management of severe hypoxemic respiratory failure. Chest 2017, 152, 867-879. [CrossRef]

27. Gupta, P.; Green, J.W.; Tang, X.; Gall, C.M.; Gossett, J.M.; Rice, T.B.; Kacmarek, R.M.; Wetzel, R.C. Comparison of high-frequency oscillatory ventilation and conventional mechanical ventilation in pediatric respiratory failure. JAMA Pediatr. 2014, 168, 243-249. [CrossRef] [PubMed]

28. Rowan, C.M.; Cristea, O.; Greathouse, S.T.; Coleman, J.J.; Nitu, M.E. Preemptive use of high-frequency oscillatory ventilation in pediatric burn patients. J. Burn Care Res. 2013, 34, 237-242. [CrossRef] [PubMed]

29. Greathouse, S.T.; Hadad, I.; Zieger, M.; Nitu, M.; Rowan, C.M.; Coleman, J.J. High-frequency oscillatory ventilators in burn patients: Experience of riley hospital for children. J. Burn Care Res. 2012, 33, 425-435. [CrossRef]

30. Jackson, M.P.; Philp, B.; Murdoch, L.J.; Powell, B.W.E.M. High frequency oscillatory ventilation successfully used to treat a severe paediatric inhalation injury. Burns 2002, 28, 509-511. [CrossRef]

31. Sen, S. Pediatric inhalation injury. Burn. Trauma 2017, 5, 31. [CrossRef]

32. Stock, M.C.; Downs, J.B.; Frolicher, D.A. Airway pressure release ventilation. Crit. Care Med. 1987, 15, 462-466. [CrossRef]

33. Habashi, N.M. Other approaches to open-lung ventilation: Airway pressure release ventilation. Crit. Care Med. 2005, 33, S228-S240. [CrossRef]

34. Fredericks, A.S.; Bunker, M.P.; Gliga, L.A.; Ebeling, C.G.; Ringqvist, J.R.; Heravi, H.; Manley, J.; Valladares, J.; Romito, B.T. Airway pressure release ventilation: A review of the evidence, theoretical benefits, and alternative titration strategies. Clin. Med. Insights Circ. Respir. Pulm. Med. 2020, 14, 1179548420903297. [CrossRef]

35. Jain, S.V.; Kollisch-Singule, M.; Sadowitz, B.; Dombert, L.; Satalin, J.; Andrews, P.; Gatto, L.A.; Nieman, G.F.; Habashi, N.M. The 30-year evolution of airway pressure release ventilation (APRV). Intensive Care Med. Exp. 2016, 4, 1-18. [CrossRef]

36. Kollisch-Singule, M.; Andrews, P.; Satalin, J.; Gatto, L.A.; Nieman, G.F.; Habashi, N.M. The time-controlled adaptive ventilation protocol: Mechanistic approach to reducing ventilator-induced lung injury. Eur. Respir. Rev. 2019, 28, 180126. [CrossRef] [PubMed]

37. Bell, L. ICU Liberation: The Power of Pain Control, Minimal Sedation, and Early Mobility; Balas, M., Clemmer, T., Hargett, K., Eds.; Society of Critical Care Medicine: Mount Prospect, IL, USA, 2015. 
38. Girard, T.D.; Kress, J.P.; Fuchs, B.D.; Thomason, J.W.; Schweickert, W.D.; Pun, B.T.; Taichman, D.B.; Dunn, J.G.; Pohlman, A.S.; Kinniry, P.A.; et al. Efficacy and safety of a paired sedation and ventilator weaning protocol for mechanically ventilated patients in intensive care (Awakening and Breathing Controlled trial): A randomised controlled trial. Lancet 2008, 371, 126-134. [CrossRef]

39. Lee, Y.-L.L.; Sims, K.D.; Butts, C.C.; Frotan, M.A.; Kahn, S.; Brevard, S.B.; Simmons, J.D. The combination of SAT and SBT protocols may help reduce the incidence of ventilator-associated pneumonia in the burn intensive care unit. J. Burn Care Res. 2017, 38, e574-e579. [CrossRef]

40. Ouellette, D.R.; Patel, S.; Girard, T.; Morris, P.E.; Schmidt, G.A.; Truwit, J.D.; Alhazzani, W.; Burns, S.M.; Epstein, S.K.; Esteban, A.; et al. Liberation from mechanical ventilation in critically ill adults: An Official American College of Chest Physicians/American Thoracic Society Clinical Practice Guideline: Inspiratory Pressure augmentation during spontaneous breathing trials, protocols minimizing sedation, and noninvasive ventilation immediately after extubation. Chest 2017, 151, 166-180. [CrossRef]

41. Smailes, S.T.; McVicar, A.; Martin, R. Cough strength, secretions and extubation outcome in burn patients who have passed a spontaneous breathing trial. Burns 2013, 39, 236-242. [CrossRef] [PubMed]

42. Smailes, S.T.; Martin, R.V.; McVicar, A.J. The incidence and outcome of extubation failure in burn intensive care patients. J. Burn Care Res. 2009, 30, 386-392. [CrossRef] [PubMed]

43. Frutos-Vivar, F.; Ferguson, N.; Esteban, A.; Epstein, S.K.; Arabi, Y.; Apezteguía, C.; González, M.; Hill, N.S.; Nava, S.; D’Empaire, G.; et al. Risk factors for extubation failure in patients following a successful spontaneous breathing trial. Chest 2006, 130, 1664-1671. [CrossRef]

44. Mitchell, V.; Dravid, R.M.; Patel, A.; Swampillai, C.; Higgs, A. Difficult airway society guidelines for the management of tracheal extubation. Anaesthesia 2012, 67, 318-340. [CrossRef]

45. Sturgess, D.J.; Greenland, K.B.; Senthuran, S.; Ajvadi, F.A.; Van Zundert, A.; Irwin, M. Tracheal extubation of the adult intensive care patient with a predicted difficult airway-A narrative review. Anaesthesia 2017, 72, 248-261. [CrossRef] [PubMed]

46. Hernández, G.; Vaquero, C.; González, P.; Subira, C.; Frutos-Vivar, F.; Rialp, G.; Laborda, C.; Colinas, L.; Cuena, R.; Fernandez, R. Effect of postextubation high-flow nasal cannula vs conventional oxygen therapy on reintubation in low-risk patients: A randomized clinical trial. JAMA 2016, 315, 1354-1361. [CrossRef]

47. Hernández, G.; Vaquero, C.; Colinas, L.; Cuena, R.; González, P.; Canabal, A.; Sanchez, S.; Rodriguez, M.L.; Villasclaras, A.; Fernandez, R. Effect of postextubation high-flow nasal cannula vs noninvasive ventilation on reintubation and postextubation respiratory failure in high-risk patients: A randomized clinical trial. JAMA 2016, 316, 1565-1574. [CrossRef] [PubMed]

48. Butterworth, J.F.; Wasnick, J.D.; Mackey, D.C. Morgan and Mikhail's Clinical Anesthesiology, 5th ed.; McGraw-Hill Education: New York, NY, USA, 2013.

49. Jaber, S.; Chanques, G.; Jung, B.; Riou, B. Postoperative noninvasive ventilation. Anesthesiology 2010, 112, 453-461. [CrossRef]

50. Endorf, F.W.; Dries, D.J. Noninvasive ventilation in the burned patient. J. Burn Care Res. 2010, 31, 217-228. [CrossRef]

51. Amato, M.B.P.; Meade, M.O.; Slutsky, A.S.; Brochard, L.; Costa, E.L.V.; Schoenfeld, D.A.; Stewart, T.E.; Briel, M.; Talmor, D.S.; Mercat, A.; et al. Driving pressure and survival in the acute respiratory distress syndrome. N. Engl. J. Med. 2015, 372, 747-755. [CrossRef]

52. Glossop, A.J.; Shepherd, N.; Bryden, D.C.; Mills, G. Non-invasive ventilation for weaning, avoiding reintubation after extubation and in the postoperative period: A meta-analysis. Br. J. Anaesth. 2012, 109, 305-314. [CrossRef]

53. Spoletini, G.; Alotaibi, M.; Blasi, F.; Hill, N.S. Heated humidified high-flow nasal oxygen in adults: Mechanisms of action and clinical implications. Chest 2015, 148, 253-261. [CrossRef] [PubMed]

54. Maggiore, S.M.; Idone, F.A.; Vaschetto, R.; Festa, R.; Cataldo, A.; Antonicelli, F.; Montini, L.; De Gaetano, A.; Navalesi, P.; Antonelli, M. Nasal high-flow versus venturi mask oxygen therapy after extubation. Effects on oxygenation, comfort, and clinical outcome. Am. J. Respir. Crit. Care Med. 2014, 190, 282-288. [CrossRef] [PubMed]

55. Roca, O.; Riera, J.; Torres, F.; Masclans, J.R. High-flow oxygen therapy in acute respiratory failure. Respir. Care 2010, 55, 408-413.

56. Hasani, A.; Chapman, T.; McCool, D.; Smith, R.; Dilworth, J.; Agnew, J. Domiciliary humidification improves lung mucociliary clearance in patients with bronchiectasis. Chronic Respir. Dis. 2008, 5, 81-86. [CrossRef] [PubMed]

57. Williams, R.; Rankin, N.; Smith, T.; Galler, D.; Seakins, P. Relationship between the humidity and temperature of inspired gas and the function of the airway mucosa. Crit. Care Med. 1996, 24, 1920-1929. [CrossRef]

58. Dysart, K.; Miller, T.L.; Wolfson, M.R.; Shaffer, T.H. Research in high flow therapy: Mechanisms of action. Respir. Med. 2009, 103, 1400-1405. [CrossRef]

59. Frizzola, M.; Miller, T.L.; Rodriguez, M.E.; Zhu, Y.; Rojas, J.; Hesek, A.; Stump, A.; Shaffer, T.H.; Dysart, K. High-flow nasal cannula: Impact on oxygenation and ventilation in an acute lung injury model. Pediatr. Pulmonol. 2011, 46, 67-74. [CrossRef] [PubMed]

60. Chung, K.K.; Rhie, R.Y.; Lundy, J.B.; Cartotto, R.; Henderson, E.; Pressman, M.A.; Joe, V.C.; Aden, J.K.; Driscoll, I.R.; Faucher, L.D.; et al. A survey of mechanical ventilator practices across burn centers in North America. J. Burn Care Res. 2016, 37, e131-e139. [CrossRef] [PubMed] 